\title{
Synthesis and infrared spectra of alkaline earth metal carbonates formed by the reaction of metal salts with urea at high temperature
}

\author{
S M TELEB ${ }^{\dagger}$, D EL-SAYED NASSR ${ }^{\dagger}$ and E M NOUR* \\ Department of Chemistry, College of Science, Qatar University, P.O. Box 2713, Doha, Qatar \\ ${ }^{\dagger}$ Department of Chemistry, Faculty of Science, Zagazig University, Zagazig, Egypt
}

MS received 4 November 2003; revised 20 September 2004

\begin{abstract}
The metal carbonate, $\mathrm{MCO}_{3}(\mathrm{M}=\mathrm{Ca}, \mathrm{Sr}$ and $\mathrm{Ba})$, was synthesized by a novel method of reacting aqueous solution of each of $\mathrm{Ca}^{2+}, \mathrm{Sr}^{2+}$ and $\mathrm{Ba}^{2+}$ salts with urea at high temperature, $\sim 80^{\circ} \mathrm{C}$. The reaction products were characterized through elemental analysis and infrared spectra. The infrared spectra of the products are the same as those of the corresponding commercially obtained carbonates. A general reaction describing the formation of $\mathrm{MCO}_{3}$ is proposed.
\end{abstract}

Keywords. Urea; alkaline earth metals; carbonates; infrared spectra.

\section{Introduction}

Urea-metal ion complexes have been the subject of many intensive investigations at room temperature. Most of these investigations deal with the synthesis and characterization of complexes of urea with transition metals (Penland et al 1957; Schafer and Curran 1966; Barbier and Hugel 1974, 1977; Srivastava and Aravindakshan 1983). However, studies on the nature of the reaction of urea with alkaline earth metals are very rare and the usual investigations of this type of reactions were performed at room temperature (Hubberstey 1988). These studies show that the ability of alkaline earths to form complexes with urea at room temperature decreases significantly as the metal ionic radius increases (Arternova et al 1985). Our previous studies (Nour and Rady 1991; Teleb 1993; Teleb et al 1993; Nour et al 1997) on the nature of the reaction of urea with metal ions at high temperature show that the decomposition mode of coordinated urea is completely different from that of free urea and that the nature of the reaction products depend upon both the type of metal ions and associated counter ions. In order to continue our investigation in this area, the reaction of urea with $\mathrm{Ca}^{2+}$, $\mathrm{Sr}^{2+}$ and $\mathrm{Ba}^{2+}$ ions, in aqueous solutions at $\sim 80^{\circ} \mathrm{C}$, was studied. The reaction products were characterized by their elemental analyses as well as infrared spectra.

\section{Experimental}

Reagent grade chemicals were used without further purification. $\mathrm{CaCO}_{3}$ was prepared by mixing equal volumes of

\footnotetext{
*Author for correspondence
}

aqueous solutions (100 ml) of $0.01 \mathrm{~mol}$ of calcium(II) salts, $\mathrm{CaCl}_{2} \cdot 2 \mathrm{H}_{2} \mathrm{O}, \mathrm{Ca}\left(\mathrm{NO}_{3}\right)_{2} \cdot 4 \mathrm{H}_{2} \mathrm{O}$ or $\mathrm{Ca}\left(\mathrm{CH}_{3} \mathrm{COO}\right)_{2} \cdot 2 \mathrm{H}_{2} \mathrm{O}$, with $100 \mathrm{ml}$ of an aqueous solution of $0.1 \mathrm{~mol}(6.0 \mathrm{~g})$ urea. The reaction mixtures were heated to $\sim 80^{\circ} \mathrm{C}$ for $2-$ $4 \mathrm{~h}$ in a water bath. The precipitated white products were filtered, washed several times with hot water, dried at $80^{\circ} \mathrm{C}$ in an oven for $3 \mathrm{~h}$, and then in vacuo over $\mathrm{P}_{2} \mathrm{O}_{5}$. The same product was obtained for the reaction of $0.01 \mathrm{~mol}$ of $\mathrm{CaSO}_{4} \cdot 2 \mathrm{H}_{2} \mathrm{O}$ with $0.3 \mathrm{~mol}$ of urea. $\mathrm{SrCO}_{3}$ and $\mathrm{BaCO}_{3}$ were prepared by a similar method using $100 \mathrm{ml}$ of an aqueous solution of $0.01 \mathrm{~mol}$ of metal salt, $\mathrm{SrCl}_{2} \cdot 6 \mathrm{H}_{2} \mathrm{O}, \mathrm{Sr}\left(\mathrm{NO}_{3}\right)_{2} \cdot 2 \mathrm{H}_{2} \mathrm{O}, \mathrm{BaCl}_{2} \cdot 2 \mathrm{H}_{2} \mathrm{O}$ or $\mathrm{Ba}\left(\mathrm{NO}_{3}\right)_{2} \cdot 2 \mathrm{H}_{2} \mathrm{O}$ with $100 \mathrm{ml}$ of an aqueous solution of $0.1 \mathrm{~mol}$ urea. Strontium and barium sulphates did not dissolve in aqueous solutions of urea and, therefore, no reaction could be observed between these ions and urea.

The carbonate content in the product, $\mathrm{MCO}_{3}$, was determined using a standardized hydrochloric acid solution. Calcium, strontium and barium ions were determined by titration with standardized EDTA in the presence of the indicator Eriochrome Black T. The infrared spectra of urea and all other reactants and products were recorded as $\mathrm{KBr}$ discs using a Perkin-Elmer 1430 ratio-recording infrared spectrophotometer.

\section{Results and discussion}

A white solid product is produced during the reaction of calcium, strontium or barium(II) ions with urea at $\sim 80^{\circ} \mathrm{C}$. The yields of the product obtained from each reaction together with the elemental analysis of $\mathrm{MCO}_{3}$ obtained from the reaction of $\mathrm{Ca}(\mathrm{II}), \mathrm{Sr}(\mathrm{II})$ and $\mathrm{Ba}(\mathrm{II})$ chlorides with urea are summarized in table 1. 
Table 1. Yield and elemental analysis data obtained for the $\mathrm{MCO}_{3}$.

\begin{tabular}{llcccc}
\hline & & \multicolumn{3}{c}{ Analyses (\%) found (calc.) } \\
\cline { 4 - 6 } Metal salt used & Product & Yield (\%) & $\mathrm{C}$ & $\mathrm{M}$ & $\mathrm{CO}_{3}^{2-}$ \\
\hline $\mathrm{CaCl}_{2} \cdot 2 \mathrm{H}_{2} \mathrm{O}$ & $\mathrm{CaCO}_{3}$ & 71 & $12 \cdot 40(12 \cdot 00)$ & $41 \cdot 30(40 \cdot 00)$ & $61 \cdot 90(60 \cdot 00)$ \\
$\mathrm{Ca}\left(\mathrm{NO}_{3}\right)_{2} \cdot 4 \mathrm{H}_{2} \mathrm{O}$ & $\mathrm{CaCO}_{3}$ & 72 & & & \\
$\mathrm{Ca}\left(\mathrm{OAc}_{2} \cdot 2 \mathrm{H}_{2} \mathrm{O}\right.$ & $\mathrm{CaCO}_{3}$ & 74 & & & \\
$\mathrm{CaSO}$ & & & & & \\
$\mathrm{H}_{2} \mathrm{O}$ & $\mathrm{CaCO}_{3}$ & $73 \cdot 5$ & & & \\
$\mathrm{SrCl}_{2} \cdot 6 \mathrm{H}_{2} \mathrm{O}$ & $\mathrm{SrCO}_{3}$ & 68 & $8 \cdot 50(8 \cdot 13)$ & $60 \cdot 20(59 \cdot 34)$ & $40 \cdot 20(40 \cdot 65)$ \\
$\mathrm{Sr}\left(\mathrm{NO}_{3}\right)_{2} \cdot 2 \mathrm{H}_{2} \mathrm{O}$ & $\mathrm{SrCO}_{3}$ & 70 & & & \\
$\mathrm{BaCl}_{2} \cdot 2 \mathrm{H}_{2} \mathrm{O}$ & $\mathrm{BaCO}_{3}$ & 63 & $5 \cdot 96(6 \cdot 09)$ & $68 \cdot 13(69 \cdot 54)$ & $29 \cdot 80(30 \cdot 45)$ \\
$\mathrm{Ba}\left(\mathrm{NO}_{3}\right)_{2} \cdot 2 \mathrm{H}_{2} \mathrm{O}$ & $\mathrm{BaCO}_{3}$ & 70 & & & \\
\hline
\end{tabular}

Table 2. Infrared frequencies $\left(\mathrm{cm}^{-1}\right)$ and assignments for urea, authentic carbonates (A) and obtained carbonates (B) formed in the reaction of $\mathrm{Ca}(\mathrm{II}), \mathrm{Sr}(\mathrm{II})$ and $\mathrm{Ba}$ (II) salts with urea.

\begin{tabular}{|c|c|c|c|c|c|c|c|}
\hline \multirow[b]{3}{*}{ Urea } & \multicolumn{6}{|c|}{$\left(\mathrm{cm}^{-1}\right)^{\mathrm{a}}$} & \multirow[b]{3}{*}{ Assignments $^{\mathrm{b}}$} \\
\hline & \multicolumn{2}{|c|}{$\mathrm{CaCO}_{3}$} & \multicolumn{2}{|c|}{$\mathrm{SrCO}_{3}$} & \multicolumn{2}{|c|}{$\mathrm{BaCO}_{3}$} & \\
\hline & (A) & (B) & (A) & (B) & (A) & (B) & \\
\hline 3450 bs & - & - & - & - & - & - & $v_{\mathrm{as}} \mathrm{NH}$ \\
\hline- & $3438 \mathrm{wb}$ & $3434 \mathrm{wb}$ & $3430 \mathrm{wb}$ & $3435 \mathrm{wb}$ & $3436 \mathrm{wb}$ & $3435 \mathrm{wb}$ & $v(\mathrm{O}-\mathrm{H}) ; \mathrm{H}_{2} \mathrm{O}, \mathrm{KB}$ \\
\hline $3350 \mathrm{bs}$ & - & - & - & - & - & - & $\mathrm{v}_{\mathrm{as}} \mathrm{NH}$ \\
\hline - & $1635 \mathrm{sh}$ & $1632 \mathrm{sh}$ & $1622 \mathrm{sh}$ & $1631 \mathrm{sh}$ & $1625 \mathrm{sh}$ & $1620 \mathrm{sh}$ & $\delta\left(\mathrm{H}_{2} \mathrm{O}\right) ; \mathrm{H}_{2} \mathrm{O}, \mathrm{KBr}$ \\
\hline $1670 \mathrm{~ms}$ & - & - & - & - & - & - & $\left\{\begin{array}{c}v \mathrm{C}=\mathrm{O} \\
\delta \mathrm{NH}_{2}\end{array}\right.$ \\
\hline - & $1457 \mathrm{sb}$ & $1459 \mathrm{sb}$ & $1450 \mathrm{sb}$ & $1456 \mathrm{sb}$ & $1484 \mathrm{sb}$ & $1485 \mathrm{sb}\}$ & $v(\mathrm{C}-\mathrm{O}) ; \mathrm{CO}_{3}^{2-}$ \\
\hline- & $1145 \mathrm{w}$ & $1140 \mathrm{w}$ & $1085 \mathrm{w}$ & $1080 \mathrm{w}$ & $1143 \mathrm{w}$ & $1158 \mathrm{w}\}$ & \\
\hline $1620 \mathrm{bs}$ & - & - & - & - & - & - & $\left\{\begin{array}{c}\delta \mathrm{NH}_{2} \\
v \mathrm{C}=\mathrm{O}\end{array}\right.$ \\
\hline- & $884 \mathrm{~s}$ & $880 \mathrm{~s}$ & $850 \mathrm{~s}$ & $847 \mathrm{~s}$ & $845 \mathrm{~s}$ & $850 \mathrm{~s} \quad\}$ & $\delta(\mathrm{OCO}) ; \mathrm{CO}_{3}^{2-}$ \\
\hline- & $719 \mathrm{~ms}$ & $707 \mathrm{~ms}$ & $710 \mathrm{~ms}$ & $723 \mathrm{~ms}$ & $708 \mathrm{~ms}$ & $704 \mathrm{~ms} S$ & \\
\hline $1465 \mathrm{~s}$ & - & - & - & - & - & - & $v \mathrm{CN}$ \\
\hline $\left.\begin{array}{l}1150 \mathrm{~s} \\
790 \mathrm{~s}\end{array}\right\}$ & - & - & - & - & - & - & $\delta_{\mathrm{r}} \mathrm{NH}_{2}$ \\
\hline $\left.\begin{array}{l}530 \mathrm{w} \\
480 \mathrm{w}\end{array}\right\}$ & - & - & - & - & - & - & $\delta \mathrm{NCN}$ \\
\hline
\end{tabular}

ab. broad; m. medium; sh. shoulder; s. strong; w. weak.

${ }^{\mathrm{b}} v$. stretching; $\delta$. bending.

The infrared spectra of the solid products are shown in figure 1 and their band assignments are given in table 2.

These spectra show no bands due to coordinated urea but a group of bands characteristic of ionic carbonate, $\mathrm{CO}_{3}^{2-}$, are present. The elemental analysis data for the products, together with their infrared spectra, indicate that they may be formulated as $\mathrm{MCO}_{3}$ where $\mathrm{M}=\mathrm{Ca}^{2+}$, $\mathrm{Sr}^{2+}$ or $\mathrm{Ba}^{2+}$. This conclusion is supported by the fact that identical infrared spectra were obtained for both the products and the corresponding commercially-available alkaline earth carbonates. Also, the infrared band assignments agree quite well with those known for the ionic carbonates (Nakamoto 1978). Obtaining the same product from the reaction of various salts of $\mathrm{Ca}^{2+}, \mathrm{Sr}^{2+}$ and $\mathrm{Ba}^{2+}$ with urea at elevated temperature indicates that these three different alkaline earth metal ions play the same role in decomposing the coordinated urea at elevated temperature. This role may be understood as follows. $\mathrm{Ca}^{2+}, \mathrm{Sr}^{2+}$ and $\mathrm{Ba}^{2+}$ ions are known to react with urea at room temperature to form complexes (Cotton and Wilkinson 1980) of the type, $\left[\mathrm{M}(\text { urea })_{4}\right]^{2+}$. However, the use of ten-fold excess of urea was necessary to ensure complete formation of the parent complex, $\left[\mathrm{M}(\text { urea })_{4}\right]^{2+}$, at room temperature. Upon heating, the excess urea will decompose to $\mathrm{CO}_{2}+\mathrm{NH}_{3}$, however, the elevated temperature of $80^{\circ} \mathrm{C}$ would facilitate expulsion of $\mathrm{CO}_{2}$ and $\mathrm{NH}_{3}$ formed, there- 


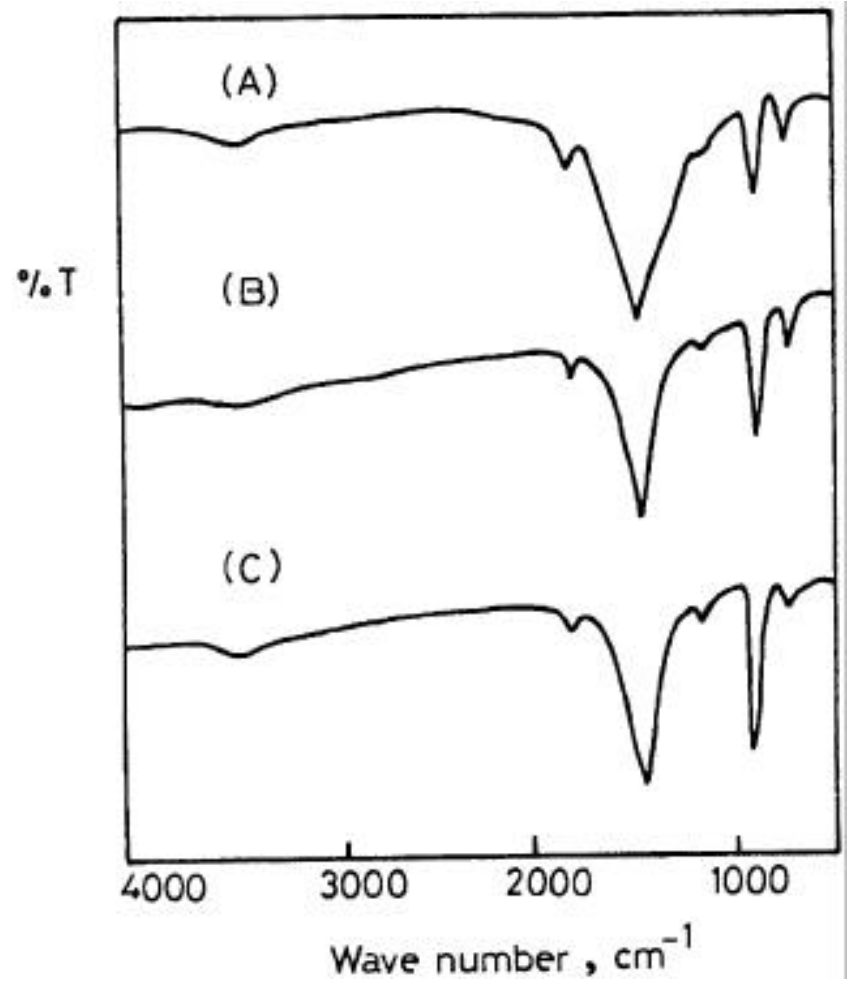

Figure 1. Infrared spectra of (A) $\mathrm{CaCO}_{3}$, (B) $\mathrm{SrCO}_{3}$ and (C) $\mathrm{BaCO}_{3}$ formed in the reaction of $\mathrm{Ca}(\mathrm{II}), \mathrm{Sr}(\mathrm{II})$ and $\mathrm{Ba}(\mathrm{II})$ chlorides, respectively, with urea at elevated temperature.

by, shifting the equilibrium to the right resulting in quantitative precipitation of metal carbonates. At elevated temperature, the following reaction may take place, giving the corresponding metal carbonate.

$$
\begin{gathered}
{\left[\mathrm{M}(\text { urea })_{4}\right] \mathrm{X}_{2}+5 \mathrm{H}_{2} \mathrm{O} \stackrel{\sim 80^{\circ} \mathrm{C}}{\rightarrow} \underset{\mathrm{MCO}_{3}+3 \mathrm{CO}_{2}+}{2 \mathrm{NH}_{4} \mathrm{X}+6 \mathrm{NH}_{3}}} \\
{\left[\begin{array}{l}
\mathrm{M}=\mathrm{Ca}^{2+}, \mathrm{Sr}^{2+} \text { or } \mathrm{Ba}^{2+} ; \mathrm{X}=\mathrm{Cl}^{-} \text {or } \mathrm{NO}_{3}^{-} \\
\mathrm{M}=\mathrm{Ca}^{2+}, \mathrm{X}=\mathrm{CH}_{3} \mathrm{COO}^{-} \text {or } 1 / 2 \mathrm{SO}_{4}^{2-}
\end{array}\right]}
\end{gathered}
$$

\section{Conclusion}

Alkaline earth metal carbonates, $\mathrm{MCO}_{3}$, are obtained by a new synthetic method involving the reactions of $\mathrm{Ca}^{2+}$, $\mathrm{Sr}^{2+}$ and $\mathrm{Ba}^{2+}$ salts with urea in aqueous solutions at $\sim 80^{\circ} \mathrm{C}$.

\section{References}

Arternova O E, Orlova V T and Lepeshkov L N 1985 Russ. J. Inorg. Chem. $\mathbf{3 0} 4$

Barbier J P and Hugel R J 1974 Inorg. Chim. Acta 1093

Barbier J P and Hugel R J 1977 J. Inorg. Nucl. Chem. 392283

Cotton F A and Wilkinson G 1980 Advanced inorganic chemistry (New York: John Wiley \& Sons) 4th ed.

Hubberstey P 1988 Coord. Chem. Rev. 8586

Nakamoto K 1978 Infrared and Raman spectra of inorganic and coordination compounds (New York: Wiley) 2nd ed

Nour E M and Rady A H 1991 Trans. Met. Chem. 16400

Nour E M, Teleb S M, Al-Khsosy N and Refat M S 1997 Synth. React. Inorg. Met.-Org. Chem. 27505

Penland R B, Mizushima S, Curran C and Quagliano J V 1957 J. Am. Chem. Soc. 791575

Schafer M and Curran C 1966 Inorg. Chem. 5256

Srivastava P C and Aravindakshan C 1983 Z. Phys. Chem. Leipzig 26461

Teleb S M 1993 Thermochim. Acta 228131

Teleb S M, Sadeek S A and Nour E M 1993 J. Phys. Chem. Solids $\mathbf{5 4} 489$ 